\title{
Southern Brazilian native fruit shows neurochemical, metabolic and behavioral benefits in an animal model of metabolic syndrome
}

\author{
Pathise Souto Oliveira ${ }^{1}$ - Vitor Clasen Chaves ${ }^{2}$. Mayara Sandrielly Pereira Soares ${ }^{3}$ - Natália Pontes Bona ${ }^{1}$. \\ Lorenço Torres Mendonça ${ }^{1}$ • Fabiano Barbosa Carvalho ${ }^{4}$ • Jessié Martins Gutierres ${ }^{4}$. Flávia Aleixo Vasconcellos ${ }^{5}$. \\ Marcia Vizzotto $^{6}$ - Andriele Vieira ${ }^{7}$ - Roselia Maria Spanevello ${ }^{3}$. Flávio Henrique Reginatto ${ }^{2}$. \\ Claiton Leoneti Lencina ${ }^{1} \cdot$ Francieli Moro Stefanello ${ }^{1,8}$
}

Received: 1 November 2017 / Accepted: 29 May 2018

(C) Springer Science+Business Media, LLC, part of Springer Nature 2018

\begin{abstract}
In this work, we evaluated the effects of Psidium cattleianum (Red Type) (PcRT) fruit extract on metabolic, behavioral, and neurochemical parameters in rats fed with a highly palatable diet (HPD) consisted of sucrose (65\% carbohydrates being $34 \%$ from condensed milk, $8 \%$ from sucrose and $23 \%$ from starch, $25 \%$ protein and $10 \%$ fat). Animals were divided into 4 groups: standard chow, standard chow + PcRT extract $(200 \mathrm{mg} / \mathrm{Kg} /$ day by gavage), HPD, HPD + extract. The animals were treated for 150 days. Concerning chemical profiling, LC/PDA/MS/MS analysis revealed cyanidin-3-O-glucoside as the only anthocyanin in the PcRT extract. Our results showed that the animals exposed to HPD presented glucose intolerance, increased weight gain and visceral fat, as well as higher serum levels of glucose, triacylglycerol, total cholesterol, LDL-cholesterol and interleukin-6. These alterations were prevented by PcRT. In addition, HPD caused an increase in immobility time in a forced swimming test and the fruit extract prevented this alteration, indicating an antidepressant-like effect. PcRT treatment also prevented increased acetylcholinesterase activity in the prefrontal cortex caused by HPD consumption. Moreover, PcRT extract was able to restore $\mathrm{Ca}^{2+}$-ATPase activity in the prefrontal cortex, hippocampus, and striatum, as well as $\mathrm{Na}^{+}, \mathrm{K}^{+}$-ATPase activity in the prefrontal cortex and hippocampus. PcRT treatment decreased thiobarbituric acid-reactive substances, nitrite, and reactive oxygen species levels and prevented the reduction of superoxide dismutase activity in all cerebral structures of the HPD group. Additionally, HPD decreased catalase in the hippocampus and striatum. However, the extract prevented this change in the hippocampus. Our results showed that this berry extract has antihyperglycemic and antihyperlipidemic effects, and neuroprotective properties, proving to be a potential therapeutic agent for individuals with metabolic syndrome.
\end{abstract}

Keywords Metabolic syndrome $\cdot$ Highly palatable diet P P. cattleianum - Natural products - Phenolic compounds · Neuroprotection

Francieli Moro Stefanello

francieli.stefanelo@ufpel.edu.br

1 Laboratório de Biomarcadores, Centro de Ciências Químicas, Farmacêuticas e de Alimentos, Universidade Federal de Pelotas, Campus Universitário s/n, Pelotas, RS, Brazil

2 Laboratório de Farmacognosia, Programa de Pós-Graduação em Biotecnologia e Biociências, Universidade Federal de Santa Catarina, Florianópolis, SC, Brazil

3 Laboratório de Neuroquímica, Inflamação e Câncer, Centro de Ciências Químicas, Farmacêuticas e de Alimentos, Universidade Federal de Pelotas, Campus Universitário s/n, Pelotas, RS, Brazil
4 Programa de Pós-Graduação em Ciências Biológicas: Bioquímica Toxicológica, Departamento de Bioquímica e Biologia Molecular, Centro de Ciências Naturais e Exatas, Universidade Federal de Santa Maria, Santa Maria, RS, Brazil

5 Laboratório de Química Aplicada a Bioativos, Centro de Ciências Químicas, Farmacêuticas e de Alimentos, Universidade Federal de Pelotas, Campus Universitário s/n, Pelotas, RS, Brazil

6 Empresa Brasileira de Pesquisa Agropecuária, Centro de Pesquisa Agropecuária de Clima Temperado, Pelotas, RS, Brazil

7 Laboratório de Fisiopatologia, Programa de Pós-Graduação em Ciências da Saúde, Universidade do Extremo Sul Catarinense, Criciúma, SC, Brazil

8 Universidade Federal de Pelotas, Campus Universitário s/n, CEP, Capão do Leão, RS 96160-000, Brazil 


\section{Introduction}

Metabolic syndrome (MetS) is characterized by a combination of cardiovascular risk factors including hyperglycemia, dyslipidemia, and insulin resistance (IR) (Auberval et al. 2017). In addition, obesity has also been involved in this syndrome and may contribute to pro-inflammatory and oxidant effects (Wellen and Thompson 2010; Auberval et al. 2017). It has been shown that highly palatable diet (HPD) stimulates food intake and, consequently, promotes alterations in homeostasis related to utilization of glucose, and may lead to hyperglycemia, IR, and fatty acid oxidation (Erlanson-Albertsson 2005).

In normal metabolism, there is a balance between oxidants and antioxidants in order to maintain redox homeostasis. However, in increased energy intake, an imbalance can occur, leading to overproduction of reactive oxygen species (ROS) and reduction of antioxidant defenses. It can result in oxidative stress, which may contribute to the development of ailments such as coronary heart disease, neurological disorders, diabetes and MetS (Paredes-Lopez et al. 2010; Da Silva et al. 2014).

Evidence suggests that inflammation as well oxidative stress present in MetS can be related to the development of neuropsychiatric disorders such as depression, anxiety, schizophrenia and bipolar disorder, supporting the importance of the brain in the physiopathology of peripheral energy balance and glucose homeostasis (Farooqui et al. 2012; Zhang and Yao 2013; Gancheva et al. 2017; Oliveira et al. 2017a, b). Furthermore, increases in ROS can lead to inhibition of the enzyme $\mathrm{Na}^{+}, \mathrm{K}^{+}$-ATPase through oxidation of groups essential for enzyme activity (Srikanthan et al. 2016). The enzymes $\mathrm{Na}^{+}, \mathrm{K}^{+}$-ATPase and $\mathrm{Ca}^{2+}$-ATPase are transmembrane proteins, known not only for the function of ion pump, but also because they are important for cellular and synaptic functions (Kirshenbaum et al. 2011; Carvalho et al. 2015; Srikanthan et al. 2016). In addition, Srikanthan and collaborators (2016) showed that the activation signaling cascade of $\mathrm{Na}^{+}, \mathrm{K}^{+}$-ATPase contributes to the worsening of obesity, dyslipidemia, diabetes, and atherosclerosis.

Acetylcholinesterase (AChE) is an enzyme responsible for the hydrolysis of the neurotransmitter acetylcholine (ACh) in cholinergic synapses (Zarros et al. 2009; Kade and Rocha 2013). The increase in the activity of this enzyme leads to a reduction in the efficiency of cholinergic neurotransmission due to a decrease in ACh levels, contributing to cognitive and neuropsychiatric disorders (Kade and Rocha 2013). In addition, an increase in $\mathrm{AChE}$ activity has been observed in animal models of diabetes and MetS, and oxidative stress seems to be involved in this increase, given that antioxidant therapies contribute to the maintenance of adequate levels of ACh in the synaptic cleft (Melo et al. 2003; Zarros et al. 2009; Kade and Rocha 2013; Oliveira et al. 2017b).
Given the variety of factors involved in the physiopathology of MetS and the use of multiple therapies, often with adverse effects, alternative therapies have been sought to prevent or control this syndrome. It has been shown that natural products have several bioactive compounds that exhibit antioxidant actions and may contribute to the prevention of diseases such as MetS, diabetes, and neuropsychiatric disorders (Devalaraja et al. 2011). Complementarily, biological activity seems be result of the combination of several compounds and thus the isolation process may lead to its loss or reduction (Williamson 2001; Raskin and Ripoll 2004; Cravotto et al. 2010; Carmona and Pereira 2013).

Psidium cattleianum Sabine Red Type (Myrtaceae) is a native fruit of Brazil that has a wide variety of uses in popular medicine, and has hypoglycemic, antibacterial, anti-inflammatory, analgesic, and central nervous system activities (Mattos Jr 1989; Inhwan et al. 2012). Additionally, these red fruits have a high content of phytochemicals such as, anthocyanins, flavonoids and phenolic acids, which also provide antioxidant properties that, can minimize oxidative damage caused by ROS (Biegelmeyer et al. 2011; Silva et al. 2014).

Studies carried out by our research group in order to seek new strategies for the control and prevention of MetS have already demonstrated that red fruit extracts such as Eugenia uniflora and Vaccinium virgatum present anti-hyperglycemic, anti-hyperlipidemic, and neuroprotective activities (Oliveira et al. 2017a, b). In this sense, the objective of this study was to investigate whether $P$. cattleianum (PcRT) fruit extract could protect rats fed with a HPD against metabolic, neurochemical, and behavioral alterations observed in MetS.

\section{Materials and methods}

\section{Phytochemicals}

\section{Extraction}

PcRT fruits were harvested in an orchard belonging to Embrapa Clima Temperado (Brazilian Agricultural Research Corporation) Pelotas/RS, Brazil. The extracts were prepared according to Bordignon et al. (2009). Unprocessed frozen PcRT fruits $(30 \mathrm{~g})$ were sonicated for $30 \mathrm{~min}$ at $25^{\circ} \mathrm{C}$ in $90 \mathrm{~mL} \mathrm{70:30} \mathrm{v} / \mathrm{v}$ ethanol-water. The $\mathrm{pH}$ of the solution was adjusted to 1.0. After this, the crude extracts were filtered, the ethanol was evaporated under reduced pressure and the remaining aqueous solution was lyophilized yielding the test samples.

\section{Total phenolic, flavonoid and anthocyanin contents}

The total phenolic content was determined according to Singleton et al. (1999), and expressed as milligrams of gallic 
acid per $1 \mathrm{~g}$ of dried extract. The total flavonoid content was measured as described by Miliauskas et al. (2004) and results were expressed as milligrams of gallic acid per $1 \mathrm{~g}$ of dried extract. Anthocyanins were quantified as described by Lee et al. (2005) and reported as milligrams of cyanidin-3-glucoside per $1 \mathrm{~g}$ of dried extract. All data were expressed as means \pm SD and analyses were performed in triplicate.

\section{Identification of anthocyanins by LC/PDA/MS/MS}

Anthocyanins were identified using an Acquity-UPLC TM coupled to a photodiode array detector (PDA) and to a highresolution mass spectrometer (Xevo® G2 QTof model WATERS®, USA). Chromatographic separation was performed using a C18 chromatography column (Synergi ${ }^{\text {TM}}$ Phenomenex®, USA) $4 \mu \mathrm{m}, 150 \times 2.0 \mathrm{~mm}$ at $40{ }^{\circ} \mathrm{C}$, and the injection volume was $5 \mu \mathrm{L}$. The elution was carried out using an aqueous solution of formic acid 2\% (solvent A) and acetonitrile with $1 \%$ of formic acid (solvent $\mathrm{B}$ ). The method used a linear gradient at constant flow rate $\left(0.4 \mathrm{~mL} \cdot \mathrm{min}^{-1}\right)$. The total time of analysis was $34 \mathrm{~min}$ according to the following conditions: 0-10 $\mathrm{min}, 5-12 \% \mathrm{~B} ; 10-29 \mathrm{~min}, 12-18 \% \mathrm{~B} ; 29-$ $33 \mathrm{~min}, 18 \% \mathrm{~B} ; 33-34 \mathrm{~min}, 5 \% \mathrm{~B}$. Detection was performed at $520 \mathrm{~nm}$, and the range of spectral scanning in the visible region was 450-600 nm (PDA). Mass spectrometry was carried out with an electrospray ionization source (ESI) set on negative ion mode, capillary voltage $1.0 \mathrm{kV}$, source block temperature $120{ }^{\circ} \mathrm{C}$, desolvation temperature $600{ }^{\circ} \mathrm{C}$; nebulizer nitrogen flow rate $80 \mathrm{~L} \mathrm{~h}^{-1}$, desolvation nitrogen gas flow $800 \mathrm{~L} \mathrm{~h}^{-1}$, and cone voltage, $40 \mathrm{~V}$, controlled by MassLynx v.4.1 software for data acquisition and processing. The mass scanning ranged from 200 to $1500 \mathrm{~m} / \mathrm{z}$ with a scan time of $0.5 \mathrm{~s}$. MS/MS analysis was performed using a collision energy ramp (10-30 eV); and with argon as the collision gas. All analyses were performed in triplicate.

\section{Animal and extract treatments}

Wistar rats aged 21 days and maintained at $21-25^{\circ} \mathrm{C}$ with free access to water and food, under a 12:12 h light:dark cycle (lights on at 7:00 a.m.) were used throughout this study. The animals were housed in groups of 3-4 per cage.

Forty male rats were divided into four groups: (1) standard chow group (SC) + vehicle, which received standard laboratory rat chow $(50 \%$ carbohydrate from starch, $22 \%$ protein and $4 \%$ fat) and water; (2) SC + PcRT, with standard laboratory rat chow and PcRT; (3) HPD + vehicle, which received a diet consisted of sucrose ( $65 \%$ carbohydrates being $34 \%$ from condensed milk, $8 \%$ from sucrose and $23 \%$ from starch, $25 \%$ protein and $10 \%$ fat) and water (4) HPD + PcRT. The treatments lasted 150 days and the dose of extract administered was $200 \mathrm{mg} / \mathrm{Kg} /$ day by gavage. The animal model of MetS and the dose of PcRT extract were based on Oliveira et al. (2017a, b). The experiments were performed after approval by the Ethics Committee of the Institution (CEEA $n^{\circ}$ 9125) and all efforts were made to minimize animal suffering.

\section{Body weight gain and food intake}

Changes in body weight and food intake patterns of rats were measured throughout the experimental period. The weight of each rat was recorded on day 0 and at weekly intervals throughout the course of the study. The quantity of food consumed by each group was recorded weekly, and the food consumption per rat was calculated for each group.

\section{Sample collection and biochemical assay}

After 150 days of food and extract administration, $24 \mathrm{~h}$ after last behavioral test and after $6 \mathrm{~h}$ of fasting the animals were euthanized by decapitation without anesthesia. At euthanasia, visceral fat was weighed and the blood collected. Serum was obtained by centrifugation at $800 \mathrm{x} \mathrm{g}\left(4^{\circ} \mathrm{C}\right)$ for $15 \mathrm{~min}$. Prefrontal cortex (PFC), hippocampus (HP), and striatum (ST) were separated and stored at $-80{ }^{\circ} \mathrm{C}$ for subsequent biochemical analyses.

\section{Glucose tolerance test}

The glucose tolerance test was performed 2 days before the euthanasia. Rats were injected intraperitoneally with $50 \%$ glucose solution to achieve $2 \mathrm{mg} / \mathrm{g}$ of body weight. The glucose levels for all the groups were estimated using a glucometer (AccuChek Active, Roche Diagnostics $®$, USA) at 30, 60, and $120 \mathrm{~min}$ after the glucose injection by a small tail puncture to collect blood.

\section{Serum biochemical parameters}

Measurements of serum glucose, total cholesterol, cholesterol-LDL, cholesterol-HDL, triacylglycerol (TAG), urea, uric acid, and alanine aminotransferase (ALT) levels were determined using commercially available diagnostic kits supplied by Labtest® (Labtest, MG, Brazil). Interleukin-6 (IL-6) quantity was assessed by ELISA using commercial kits (R\&D Systems) according to the manufacturer's instructions.

\section{Behavioral analysis}

\section{Open-field test}

Ambulatory behavior was assessed in an open-field test as previously described by Gazal et al. (2015). The experimental apparatus consisted of a box measuring $40 \times 60 \times 50 \mathrm{~cm}$. with the floor of the arena divided into 12 equal squares and placed in a sound-free room. Animals were placed in the rear left 
square and left to freely explore for 5 min during which time the number of squares crossed with all paws (crossing) was counted.

\section{Forced swimming test (FST)}

Depressive-like behavior was evaluated by the total duration of immobility in the forced swimming test, as previously described Huynh et al. (2011). Rats were individually forced to swim in an open cylindrical container $45 \mathrm{~cm}$ high and $20 \mathrm{~cm}$ in diameter and depth of $30 \mathrm{~cm}$, with water at $22 \pm 1{ }^{\circ} \mathrm{C}$ and the total duration of immobility during a $5 \mathrm{~min}$ period was scored: rats were judged to be immobile when they ceased struggling and remained floating motionless in the water, making only those movements necessary to keep the head above water.

\section{Tissue preparation}

Prefrontal cortex (PFC), hippocampus (HP), and striatum (ST) were homogenized in sodium phosphate buffer, $\mathrm{pH} 7.4$, containing $\mathrm{KCl}$. The homogenates were centrifuged at $800 \times g$ for $10 \mathrm{~min}$ at $4{ }^{\circ} \mathrm{C}$ and the supernatant was used for neurochemical analyses. Protein concentration was determined by the method of Lowry et al. (1951) or Bradford (1976).

\section{Acetylcholinesterase (AChE) activity}

AChE activity was determined as described in the colorimetric method of Ellman et al. (1961) with modifications and expressed as $\mu \mathrm{mol} \mathrm{AcSCh} / \mathrm{h} / \mathrm{mg}$ of protein.

\section{Determination of $\mathrm{Ca}^{2+}$-ATPase and $\mathrm{Na}^{+}, \mathrm{K}^{+}$-ATPase activities}

$\mathrm{Na}^{+}, \mathrm{K}^{+}$-ATPase and $\mathrm{Ca}^{+2}$-ATPase activities were measured in the cerebral structures as described by Carvalho et al. 2015. The amount of inorganic phosphate (Pi) released was quantified colorimetrically, using $\mathrm{KH}_{2} \mathrm{PO}_{4}$ as the reference standard (Fiske and Subbarow 1927). The absorbance was measured at $630 \mathrm{~nm}$.

The specific $\mathrm{Na}^{+}, \mathrm{K}^{+}$-ATPase activity was calculated by subtracting the ouabain-insensitive activity from the overall activity (in the absence of ouabain) and was expressed in nmol of $\mathrm{Pi} / \mathrm{min} / \mathrm{mg}$ of protein. Different concentrations of ouabain were used to evaluate the activity of isoforms of $\mathrm{Na}^{+}, \mathrm{K}^{+}$ATPase. For this purpose, a classical pharmacological approach was used based on the isoform-specific sensitivity to ouabain (Nishi et al. 1999). The experiments were performed as previously described (Rambo et al. 2012). To determine if treatments alter ouabain-sensitive ATPase activity, $3 \mu \mathrm{M}$ or $4 \mathrm{mM}$ ouabain was used (so as to only inhibit the $\mathrm{Na}^{+}, \mathrm{K}^{+}$-
ATPase isoforms containing subunits $\alpha 2 / \alpha 3$, or to inhibit all isoforms, respectively).

The $\mathrm{Ca}^{2+}$-ATPase activity was determined by subtracting the activity measured in the presence of $\mathrm{Ca}^{2+}$ from that determined in the absence of $\mathrm{Ca}^{2+}$ (no added $\mathrm{Ca}^{2+}$ plus $0.1 \mathrm{mM}$ EGTA) and was expressed in $\mathrm{nmol}$ of $\mathrm{Pi} / \mathrm{min} / \mathrm{mg}$ of protein.

\section{Oxidative stress parameters}

\section{Thiobarbituric acid-reactive substances (TBARS)}

TBARS, a measure of lipid peroxidation, was determined according to the method described by Ohkawa et al. (1979) and reported as nmol TBARS/mg of protein.

\section{Reactive oxygen species (ROS)}

ROS formation was determined according to Ali et al. (1992). In this assay, the oxidation of dichloro-dihydro-fluorescein diacetate (DCFH-DA) to fluorescent dichlorofluorescein (DCF) was measured. DCF fluorescence intensity emission was recorded at 525 and $488 \mathrm{~nm}$ excitation $60 \mathrm{~min}$ after the addition of DCFH-DA to the medium. ROS levels were expressed as $\mu \mathrm{mol} \mathrm{DCF} / \mathrm{mg}$ of protein.

\section{Nitrite assay}

Nitrite concentrations were measured using the Griess reaction as described by Huang et al. 2009. For this reaction, $50 \mu \mathrm{L}$ of sample was reacted with $50 \mu \mathrm{L}$ Griess reagent for $10 \mathrm{~min}$ at room temperature. The absorbance was measured at $540 \mathrm{~nm}$ using a 96-well microplate reader and the amount of nitrite in the supernatant was compared to a standard curve of known concentrations of sodium nitrate.

\section{Total thiol content assay}

This assay was performed as described by Aksenov and Markesbery (2001). Results were reported as nmol TNB/mg of protein.

\section{Antioxidant enzyme activities}

Catalase (CAT) activity was assayed according to Aebi (1984) based on the decomposition of $\mathrm{H}_{2} \mathrm{O}_{2}$. Superoxide dismutase (SOD) activity was measured by the method described by Misra and Fridovich (1972) which is based on the inhibition of superoxide-dependent adrenaline auto-oxidation. Glutathione peroxidase (GPx) activity was measured using a commercially available diagnostic kit supplied by (RANSEL®; Randox Lab, Antrim, United Kingdom). Enzyme activities were reported as units/mg of protein. 


\section{Statistical analysis}

Measured values were expressed as means \pm S.E.M. Glucose tolerance was analyzed by repeated measures ANOVA and Bonferroni's post-hoc correction. The interaction between groups was determined by two-way ANOVA followed by Bonferroni's post-hoc test. A value of $P \leq 0.05$ was considered to be statistically significant. Analyses were performed using the software GraphPad PRISM 5®.

\section{Results}

\section{Phytochemical characterization}

According to the phytochemical characterization results, the total phenolic content in PcRT was $16.72 \pm 0.26 \mathrm{mg} / \mathrm{g}$ of dried extract. As to the total flavonoid content, $15.24 \pm 2.09 \mathrm{mg} / \mathrm{g}$ of dried extract was detected. In addition, anthocyanin content was $2.48 \pm 0.09 \mathrm{mg} / \mathrm{g}$ of dried extract. Analysis by LC/PDA/ MS/MS showed only the presence of cyanidin-3-O-glucoside in the fruit extract captured at $515 \mathrm{~nm}$ and with a retention time of $8.49 \mathrm{~min}$. The chemical structure of anthocyanin was identified by comparison with the MS/MS data of the standard samples. The anthocyanin mass and main fragmentation figures were $[\mathrm{M}]^{+} 449.1065 \mathrm{~m} / \mathrm{z}$ (error ppm: -4.2$)$ and $287(\mathrm{~m} / \mathrm{z})$, respectively.

\section{Metabolic status}

As shown in Fig. 1a, HPD induced impaired glucose tolerance $(P<0.01)$, and treatment with PcRT prevented this change in the animals submitted to the HPD. The same profile was observed in area-under-curve (A.U.C) analysis (Fig. 1b). Moreover, two-way ANOVA showed significant differences between the groups, suggesting that the PcRT treatment prevented the increase of some metabolic parameters such as weight gain $[F(1,25)=11.63 ; P<0.01]$, visceral fat mass $[F(1,27)=5.18 ; P<0.05]$, blood glucose levels $[F(1,15)=$ 5.12; $P<0.05]$, total cholesterol $[F(1,21)=25.79 ; P<$ $0.001]$, cholesterol-LDL $[F(1,13)=92.24 ; P<0.001]$, TAG $[F(1,13)=6.34 ; P<0.05]$ and IL-6 $[F(1,16)=68.39 ; P<$ $0.001]$ caused by HPD. There were no significant differences between any of the groups tested for cholesterol-HDL, urea, uric acid, and ALT $(P>0.05)$ (Table 1).

\section{Behavioral parameters}

Two-way ANOVA showed that PcRT treatment prevented the increase in immobility time in the FST induced by consumption of HPD $[F(1,23)=10.69, P<0.01]$ (Fig. 2a). In order to rule out nonspecific motor effects that could influence activity in the FST, rats were also submitted to an open-

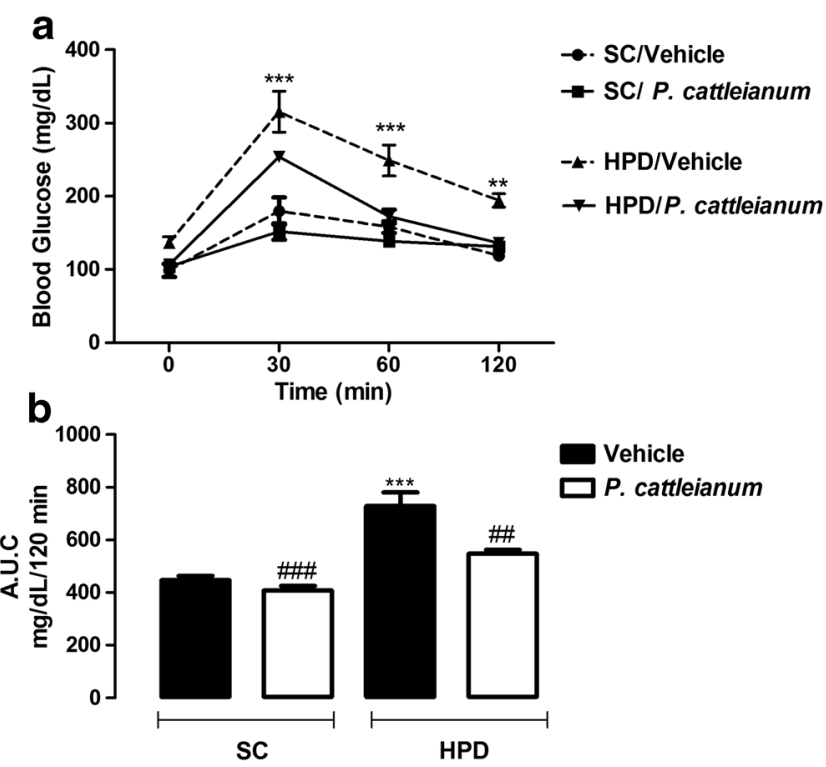

Fig. 1 Glucose tolerance test measured at the baseline (0), 30, 60 and $120 \mathrm{~min}$ after glucose injection ( $2 \mathrm{mg} / \mathrm{g}$ body weight) (a) and the respective area-under-curve $(\mathbf{b})$. Data are expressed as mean \pm S.E.M. ( $n=5$ for group). (***) $P<0.001$ compared with vehicle/SC. (**) $P<$ 0.01 compared with vehicle/SC. $\left({ }^{\# \#}\right) P<0.001$ when compared with vehicle/HPD. $\left({ }^{\# \#}\right) \quad P<0.01$ when compared with vehicle/HPD. Repeated measures ANOVA and one-way ANOVA followed by Bonferroni post-hoc test. SC = Standard Chow; HPD = Highly Palatable Diet

field test (Fig. 2b). Statistical analysis did not reveal an interaction between groups in this task $[F(1,24)=2.00 P>0.05]$, suggesting that the effects of PcRT treatment in the FST are not related to changes in locomotor activity.

\section{Neurochemical parameters}

Table 2 shows that PcRT treatment prevented the increase in the AChE activity caused by consumption of HPD in the PFC since two-way ANOVA revealed interaction between the groups $[F(1,17)=8.85, P<0.01]$. However, this enzyme activity was not altered in the $\operatorname{HP}[F(1,10)=78.21, P>0.05]$ and ST $[F(1,13)=1.53, P>0.05]$.

With regard to ATPase activity, two-way ANOVA showed a significant interaction between experimental groups, suggesting that PcRT prevented a decrease in the activity of $\mathrm{Ca}^{2+}$-ATPase in PFC $[F(1,12)=12.63, P<0.01]$, HP $[F(1,12)=27.48, P<0.001]$ and ST $[F(1,11)=25.60, P<$ $0.001]$ induced by HPD (Fig. 3a, b and c).

The effect of fruit extract and HPD on the total $\mathrm{Na}^{+}, \mathrm{K}^{+}$ATPase activity and its isoforms in the cerebral structures of rats is demonstrated in Fig. 4. Two-way ANOVA revealed significant differences between the experimental groups, suggesting that the PcRT treatment prevented the decrease in total $\mathrm{Na}^{+}, \mathrm{K}^{+}$-ATPase $\left.[F(1,14)=7.85, P<0.01]\right), \alpha 2,3-[F(1,12)=$ $9.48, P<0.01])$ and $\alpha 1$-isoform activities $[F(1,12)=14.93$, $P<0.01]$ caused by HPD consumption. In HP (Fig. 4d, e, 
Table 1 Effect of $P$. cattleianum (red type) fruit extract treatment in rats exposed to a highly palatable diet on metabolic parameters

\begin{tabular}{lllll}
\hline & SC/Vehicle & SC/P. cattleianum & HPD/Vehicle & HPD/P. cattleianum \\
\hline Weight gain (g) & $373 \pm 21.35$ & $394 \pm 11.70^{\# \#}$ & $475 \pm 19.64^{* * *}$ & $389 \pm 5.85^{\# \#}$ \\
Visceral fat mass (g) & $15.66 \pm 1.85$ & $11.33 \pm 1.74^{\# \# \#}$ & $38.33 \pm 4.92^{* * *}$ & $20.89 \pm 1.07^{\# \# \#}$ \\
Glucose (mg/dL) & $77.40 \pm 3.79$ & $77.26 \pm 1.09^{\# \# \#}$ & $131.73 \pm 7.11^{* * *}$ & $103.64 \pm 2.18^{\#}$ \\
Total cholesterol (mg/dL) & $105.91 \pm 3.87$ & $100.17 \pm 2.27^{\# \# \#}$ & $156.85 \pm 5.71^{* * *}$ & $103.99 \pm 1.13^{\# \# \#}$ \\
LDL-cholesterol (mg/dL) & $46.77 \pm 2.53$ & $41.05 \pm 5.34^{\# \# \#}$ & $100.30 \pm 2.82^{* * *}$ & $31.21 \pm 1.18^{\# \# \#}$ \\
HDL-cholesterol (mg/dL) & $49.47 \pm 1.95$ & $55.09 \pm 5.30$ & $43.37 \pm 3.47$ & $51.18 \pm 0.69$ \\
Triacylglycerol (mg/dL) & $58.62 \pm 7.16$ & $21.81 \pm 5.82^{* *}$ & $98.00 \pm 3.20^{* *}$ & $29.54 \pm 8.82^{\# \#}$ \\
Urea (mg/dL) & $66.18 \pm 3.73$ & $64.61 \pm 3.85$ & $53.32 \pm 2.53$ & $52.86 \pm 3.06$ \\
Uric acid (mg/dL) & $1.01 \pm 0.09$ & $1.05 \pm 0.09$ & $0.68 \pm 0.10$ & $0.98 \pm 0.05$ \\
ALT (U/mL) & $39.96 \pm 0.17$ & $37.19 \pm 0.29$ & $36.13 \pm 0.88$ & $37.25 \pm 0.45$ \\
IL-6 (pg/mg protein) & $0.76 \pm 0.04$ & $0.71 \pm 0.01$ & $1.35 \pm 0.05 * * *$ & $0.60 \pm 0.06^{\# \# \#}$ \\
\hline
\end{tabular}

Data are expressed as mean \pm S.E.M. $(\mathrm{n}=5-8) .(* * *) P<0.001$ as compared with the SC/Vehicle. $(* *) P<0.01$ as compared with SC/Vehicle. ${ }^{\# \# \#) ~} P<0.001$ as compared with HPD/Vehicle. ${ }^{\#}$ ) $P<0.05$ as compared with HPD/Vehicle. $\mathrm{SC}=$ Standard Chow; HPD = Highly Palatable Diet. Two-way ANOVA followed by Bonferroni post-hoc test and f), the activity of total $\mathrm{Na}^{+}, \mathrm{K}^{+}$-ATPase $[F(1,13)=12.56$, $P<0.01]$ and $\alpha 2,3$-isoform $[F(1,12)=7.08, P<0.05]$ was reduced by HPD consumption, and PcRT was able to restore ion pump activities. However, statistical analysis (two-way ANOVA) did not show an interaction $[F(1,12)=1.20, P>$ $0.05]$ in $\alpha 1-\mathrm{Na}^{+}, \mathrm{K}^{+}$-ATPase but a significant main effect of HPD $[F(1,12)=27.04, P<0.001]$. Additionally, we did not observe significant differences in the activity of total $\mathrm{Na}^{+}, \mathrm{K}^{+}-$ ATPase $[F(1,13)=0.45, P>0.05], \alpha 2,3-[F(1,13)=0.95, P>$ $0.05]$ and $\alpha 1$ isoforms $[F(1,13)=0.69, P>0.05]$ in the ST (Fig. 4g, h and i).

Two-way ANOVA showed a significant interaction between experimental groups, suggesting the effect of PcRT administration on certain oxidative stress parameters in the cerebral structures of animals exposed to HPD. We observed that PcRT was able to prevent the increase in TBARS levels in HP $[F(1,17)=9.53, P<0.01]$, ST $[\mathrm{F}(1,22)=4.47, P<0.05]$ and PFC $[F(1,21)=10.23, P<0.05]$. The same effect was observed for ROS levels in HP $[F(1,11)=21.59, P<0.001]$, ST $[\mathrm{F}(1,13)=67.84, P<0.001]$ and PFC $[F(1,18)=12.28$, $P<0.01]$. The increase in nitrite levels was prevented by PcRT in HP $[F(1,13)=13.11, P<0.01]$ and ST $[\mathrm{F}(1,14)=$ $9.50, P<0.01]$. However, although there is no interaction between groups, two-way ANOVA revealed that PcRT reduced the nitrite concentrations enhanced by HPD consumption in PFC (PcRT: $[F(1,15)=10.47, P<0.01]$, HPD: $[F(1,15)=$ $7.91, P<0.05])$. In contrast, two-way ANOVA did not show any significant differences in total thiol content in PFC $[F(1,19)=0.48, P>0.05]$ and $\operatorname{HP}[F(1,23)=0.23, P>0.05]$. In ST, no interaction between groups was demonstrated, but a significant main effect of HPD in total thiol content $[\mathrm{F}(1,15)=$ 34.82, $P<0.001$ ] (Table 3) was recognized.

In addition, we evaluated the activity of antioxidant enzymes in brain structures, and two-way ANOVA showed that
PcRT treatment prevented the diminution of SOD activity in $\operatorname{PFC}[F(1,20)=7.36, P<0.05], \mathrm{HP}[F(1,31)=4.66, P<0.05]$ and ST $[F(1,22)=9.38, P<0.01]$ caused by consumption of HPD. Moreover, PcRT treatment prevented the reduction of CAT activity caused by HPD in HP $[F(1,20)=4.53, P<0.05]$. However, statistical analysis did not show an interaction in ST, but a significant main effect of $\operatorname{HPD}[\mathrm{F}(1,19)=5.77$, $P<0.05]$. Furthermore, we did not observe any significant difference in the activity of cortical CAT $[F(1,18)=1.73$, $P>0.05]$, or in GPx activity from PFC $[F(1,25)=0.01, P>$ $0.05]$, HP $[F(1,16)=0.51, P>0.05]$ and ST $[F(1,16)=0.60$, $P>0.05]$ (Table 3).

\section{Discussion}

The berries represent a variety of small fruits characterized by purple, blue or red color and contain high levels of polyphenols, including anthocyanins, flavonoids, and other phenolic compounds (Vendrame et al. 2016). The PcRT is a berry belonging to the family Myrtaceae and is popularly known to demonstrate important antioxidant, anti-inflammatory, and hypoglycemic action due to the presence of bioactive compounds such as polyphenols (Inhwan et al. 2012; Ribeiro et al. 2014). We detected a single anthocyanin in the extract, cyanidin-3-glycoside, a widely found pigment responsible for the color of berries. This finding is relevant in a native berry from the south of Brazil since cyanidin-3-glucoside has been reported as responsible for several beneficial activities involving parameters linked to MetS (Bhaswant et al. 2015).

In the present work, we evaluated the effects of treatment with PcRT fruit extract on metabolic, neurochemical, and behavioral parameters in animals subjected to the MetS model 
a
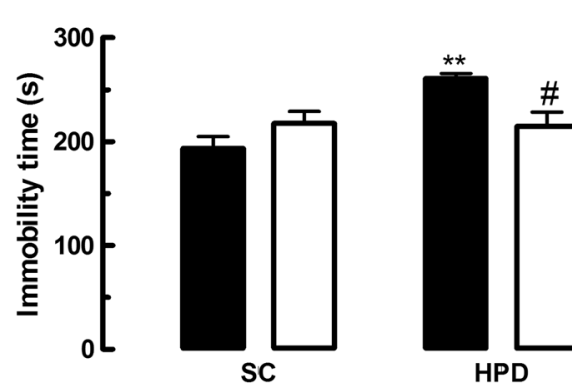

$\stackrel{0}{0}^{80}$

Open-field
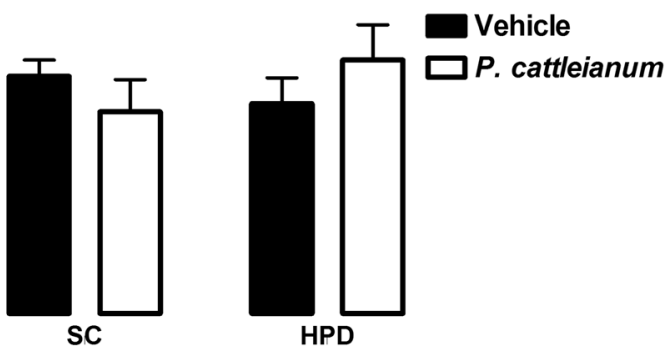

Fig. 2 Effect of P. cattleianum (red type) fruit extract treatment in rats exposed to a highly palatable diet on ambulatory behavior in immobility time in the FST (a) and open-field test (b). Results are expressed as mean \pm S.E.M. ( $n=9-10$ for group). (**) $P<0.01$ when compared with vehicle/SC. $\left({ }^{\#}\right) P<0.05$ when compared with vehicle/HPD. Two-way ANOVA followed by Bonferroni post-hoc test. SC = Standard Chow; HPD $=$ Highly Palatable Diet

induced by the consumption of HPD. PcRT extract was able to prevent some of the metabolic changes induced by HPD, such as weight gain and visceral fat accumulation, glucose intolerance, hyperglycemia, and dyslipidemia. In accordance, clinical and preclinical studies have shown a reduction of glycemic index and beneficial effects in lipid metabolism by guava, belonging to Psidium genus (Batista et al. 2018; Tey et al. 2017). It has been reported that increased TAG may cause reduction in peripheral insulin action (Khanal et al. 2012). In addition, it is likely that the weight gain observed in animals receiving HPD is related to increased visceral fat, since fat accumulation in this region has been reported as a determinant factor in the development of IR and MetS (Wellen and Thompson 2010; Khanal et al. 2012). Moreover, increased visceral fat leads to increased production of proinflammatory cytokines such as tumor necrosis factor (TNF- $\alpha$ ), interleukin1 beta (IL-1 $\beta$ ), C-reactive protein (CRP) and IL-6 (Bullo et al. 2007; Shah et al. 2008; Jayarathne et al. 2017). We observed that HPD increased IL-6 levels and PcRT extract was able to prevent this change. Furthermore, data in the literature have demonstrated that elevated levels of IL- 6 have been associated with an increased risk of diabetes, obesity and neuropsychiatric disorders (Bullo et al. 2007; Rudolf et al. 2014; Jayarathne et al. 2017).

Bioactive compounds present in PcRT fruits such as phenolic compounds have an important effect on insulin signaling as well as on the reduction of weight, glucose, TAG, total cholesterol and LDL-cholesterol (Collins et al. 2016; Bhaswant et al. 2015; Vendrame et al. 2016). The mechanisms underlying the actions of polyphenols present in $P$. cattleianum fruit extract are not well elucidated; however, some studies suggest that these compounds may inhibit digestive enzymes such as $\alpha$-amylase and the absorption of glucose in the intestine (Hanhineva et al. 2010). Polyphenols such as quercetin and phenolic acids also act on the inhibition of sodium dependent glucose (SGLT1) and GLUT2 transporters. Inhibition of these glucose transporters could attenuate glucose level excursions after a meal (Manzano and Williamson 2010). Furthermore, some studies have reported that cyanidin3-glycoside may increase fatty acid oxidation through AMPactivated protein kinase (AMPK) signaling. Activation of AMPK leads to the phosphorylation and inactivation of acetyl-CoA carboxylase, increasing fatty acid oxidation, and leading to decreased visceral fat and improved glucose metabolism (Guo et al. 2010; Bhaswant et al. 2015).

It is known that polyphenols present in the fruits of PcRT have important antioxidant and anti-inflammatory actions (Madani et al. 2015; Jayarathne et al. 2017). In addition, dietary interventions with compounds such as anthocyanins and flavonoids may modulate several systems that likely improve glucose homeostasis and insulin sensitivity (Bagul et al. 2012; Vendrame et al. 2016). In this sense, we observed that the consumption of HPD increased the levels of ROS, TBARS, and nitrite levels in the brain tissues tested, and that the treatment with PcRT was able to prevent the damage caused by
Table 2 Effect of $P$. cattleianum (red type) extract treatment in rats exposed to a highly palatable diet on acetylcholinesterase (AChE) activity in the prefrontal cortex, hippocampus and striatum

\begin{tabular}{lllll}
\hline AChE ( $\mu \mathrm{mol}$ AcSCh/h/mg of protein) & & & \\
\hline & SC/Vehicle & SC/ P. cattleianum & HPD/Vehicle & HPD/ P. cattleianum \\
\hline Prefrontal cortex & $1.24 \pm 0.118$ & $1.13 \pm 0.036$ & $1.71 \pm 0.091^{*}$ & $1.04 \pm 0.104^{\# \# \#}$ \\
Hippocampus & $1.25 \pm 0.012$ & $1.32 \pm 0.043$ & $1.17 \pm 0.087$ & $1.35 \pm 0.043$ \\
Striatum & $6.07 \pm 0.164$ & $6.30 \pm 0.236$ & $5.37 \pm 0.463$ & $5.01 \pm 0.079$ \\
\hline
\end{tabular}

Data are expressed as mean \pm S.E.M. $(n=4-6) .(*) P<0.05$ as compared with SC/Vehicle. $\left({ }^{\# \# \#) ~} P<0.001\right.$ as compared with HPD/Vehicle. $\mathrm{SC}=$ Standard Chow; HPD $=$ Highly Palatable Diet. Two-way ANOVA followed by Bonferroni post-hoc test 
HPD. We also demonstrated a reduction of thiol content in ST of animals exposed to HPD. Corroborating our findings, some data demonstrated that an increase of energy intake might lead to enhanced ROS in metabolically-active tissues such as the brain, causing lipid peroxidation and increased glucose oxidation (Madani et al. 2015; Treviño et al. 2015). It is also known that the brain uses a significant amount of oxygen and adenosine triphosphate resulting in a high susceptibility to oxidative stress (Halliwell and Gutteridge 2007). In addition, high nitric oxide levels, both in animals and in diabetic humans, can induce oxidative damage through the formation of peroxynitrite (Bagul et al. 2012). We also evaluated the activity of the antioxidant enzymes SOD, CAT, and GPx and verified that the consumption of HPD was able to decrease the activity of the antioxidant enzyme SOD in all tissues studied.
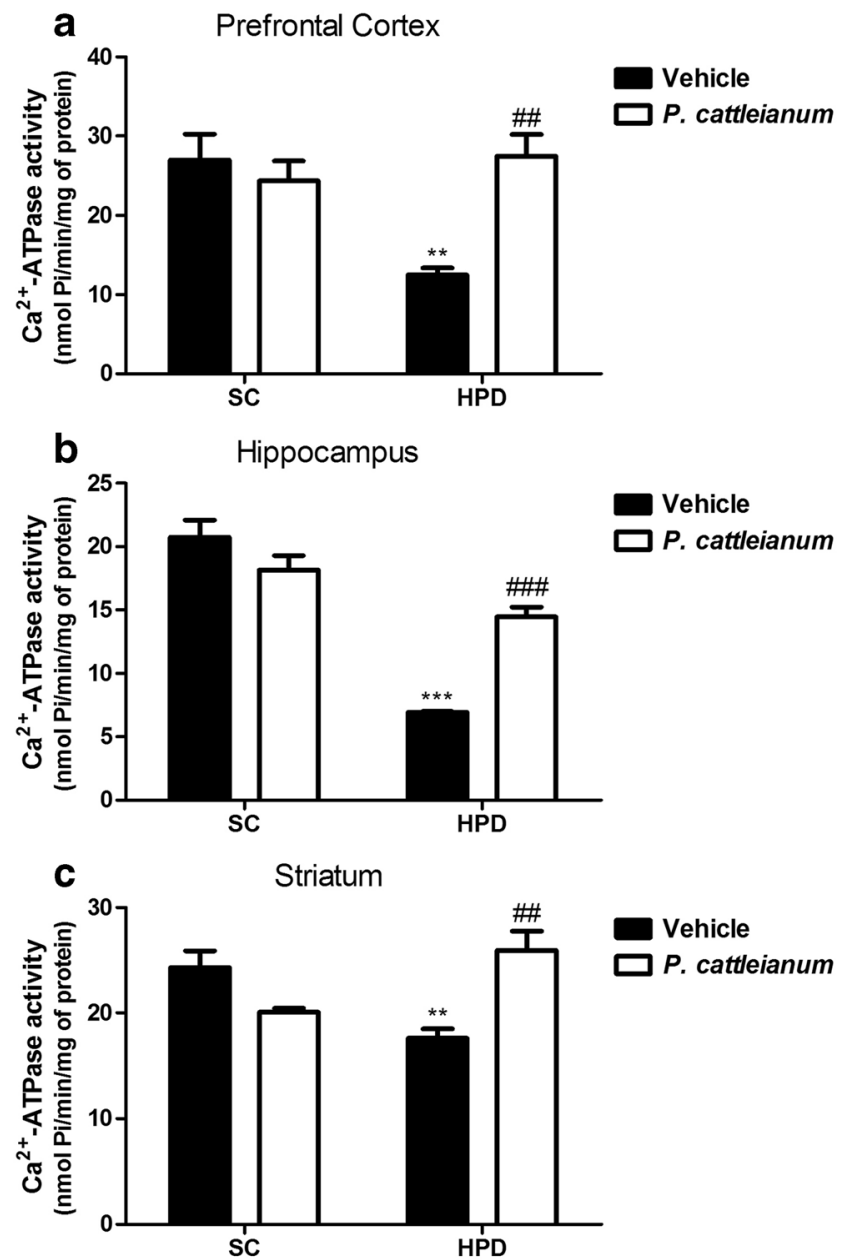

Fig. 3 Effect of $P$. cattleianum (red type) fruit extract treatment in rats exposed to a highly palatable diet on $\mathrm{Ca}^{2+}$-ATPase activity in prefrontal cortex (a), hippocampus (b) and striatum (c). Results are expressed as mean \pm S.E.M. $(n=5-6$ for group). (***) $P<0.001$ when compared with vehicle/SC. (**) $P<0.01$ when compared with vehicle/SC. $\left({ }^{\# \#}\right)$ $P<0.001$ when compared with vehicle/HPD. $\left({ }^{\# \#}\right) P<0.01$ when compared with vehicle/HPD. Two-way ANOVA followed by Bonferroni post-hoc test. $\mathrm{SC}=$ Standard Chow; HPD = Highly Palatable Diet
However, treatment with PcRT was able to prevent this reduction. Furthermore, we observed that HPD consumption decreased the activity of the antioxidant enzyme CAT only in the ST and HP of the animals tested. In contrast, treatment with PcRT extract prevented the decrease in the activity of this enzyme only in the HP of the animals tested. Data in the literature also demonstrate a significant decrease in antioxidant enzymes such as SOD and CAT in brain tissues such as PFC, HP, and ST of animals fed HPD (Treviño et al. 2015; Oliveira et al. 2017a; Oliveira et al. 2017b).

Recently, it has been suggested that MetS may cause neuropsychiatric complications such as depression, since chronic hyperglycemia and IR can trigger an inflammatory state and oxidative stress inducing neurotransmitter oxidation, neuroinflammation and neural death (Farooqui et al. 2012; Treviño et al. 2015; Oliveira et al. 2017a, b; Gancheva et al. 2017). Hence, we evaluated the depressive-like behavior of animals that received HPD and observed that the consumption of this diet increased the immobility time in the FST indicating a depressive-like behavior. However, treatment with PcRT extract prevented this alteration. Corroborating our findings, some studies have demonstrated an antidepressant-like effect of certain berries (Kumar et al. 2012; Oliveira et al. 2017a, b). In addition, Gancheva et al. (2017) also demonstrated an increase in the time of immobility in FST of animals submitted to a diet enriched with saturated fat and fructose, indicating a depressive-like behavior, which in turn correlated with the metabolic effect of diet, especially with lipid peroxidation. Moreover, it has been suggested that the increase in the production of pro-inflammatory cytokines mainly produced by visceral adipose tissue has shown a positive correlation between obesity and neuropsychiatric disorders (Ambrósio et al. 2018). In fact, in our study we observed an increase in serum levels of IL-6 in animals submitted to HPD.

In an attempt to clarify the behavioral changes found in our study, we evaluated the influence of HPD and PcRT on the activity of $\mathrm{Na}^{+}, \mathrm{K}^{+}$-ATPase and its $\alpha 1, \alpha 2$, and $\alpha 3$ isoforms in the PFC, HP, and ST. Thus, we observed that the consumption of HPD significantly decreased the activity of this enzyme in PFC and HP and that the treatment with PcRT was able to restore enzyme activity. Corroborating our findings, Gamaro et al. (2003) and Quines et al. (2016) have also demonstrated an association between the reduction of $\mathrm{Na}^{+}, \mathrm{K}^{+}$-ATPase and the increase of FST immobility time in animals submitted to a model of depression, reinforcing the hypothesis that changes in the activity of this enzyme may be related to behavioral alterations. Besides, $\mathrm{Na}^{+}, \mathrm{K}^{+}$-ATPase is responsible for maintaining the cellular electrochemical balance, which is fundamental in the differentiation of the nervous system. However, a decrease in its catalytic activity directly compromises neural function (Carvalho et al. 2015; Quines et al. 2016).

$\mathrm{Ca}^{2+}$-ATPase is also an important enzyme and plays a role in maintaining electrolyte balance in all mammals. This 
enzyme regulates the concentration of intracellular $\mathrm{Ca}^{2+}$ since its accumulation can damage the cell (Carvalho et al. 2015). In this regard, we observed that the consumption of HPD decreased enzymatic activity in all tissues tested. On the other hand, treatment with PcRT prevented this decrease. The neuroprotective effect of the PcRT extract may be related to its antioxidant activity, since these enzymes are involved in the maintenance of the ionic gradient across the cell membrane and, therefore, its inhibition can be attributed to cell membrane lipoperoxidation and ROS increase, which may lead to the oxidation of groups essential for enzymatic activity (Sharma et al. 2009; Carvalho et al. 2015; Srikanthan et al. 2016). Carvalho et al. (2015) also related the decrease in $\mathrm{Ca}^{2+}$ ATPase and $\mathrm{Na}^{+}, \mathrm{K}^{+}$-ATPase activity to the increase of oxidative stress markers. Data in the literature have demonstrated significant increases in AChE activity in brain structures of animals with metabolic diseases and dysfunctions in the central nervous system (Zarros et al. 2009; Liapi et al. 2010;
Oliveira et al. 2017b). We can speculate that the increase in this enzyme activity observed in PFC of the animals exposed to HPD may be related to a disturbance in $\mathrm{Ca}^{2+}$ homeostasis, since the influx of this ion leads to an increase in ROS production and, consequently, lipid peroxidation, which can cause a change in the conformational state of the enzyme (Melo et al. 2003). This fact would also explain the prevention of increased AChE activity by treatment with PcRT extract which has shown antioxidant effects.

In summary, our findings demonstrate that treatment with PcRT extract prevented the development of MetS induced by HPD, since it improved the body composition and demonstrated anti-hyperglycemic and anti-hyperlipidemic effects. In addition, the extract prevented the development of behavioral and neurochemical changes observed in this pathology. Thus, we can suggest that PcRT extract has neuroprotective properties, proving to be a potential therapeutic agent for individuals with MetS (Fig. 5).
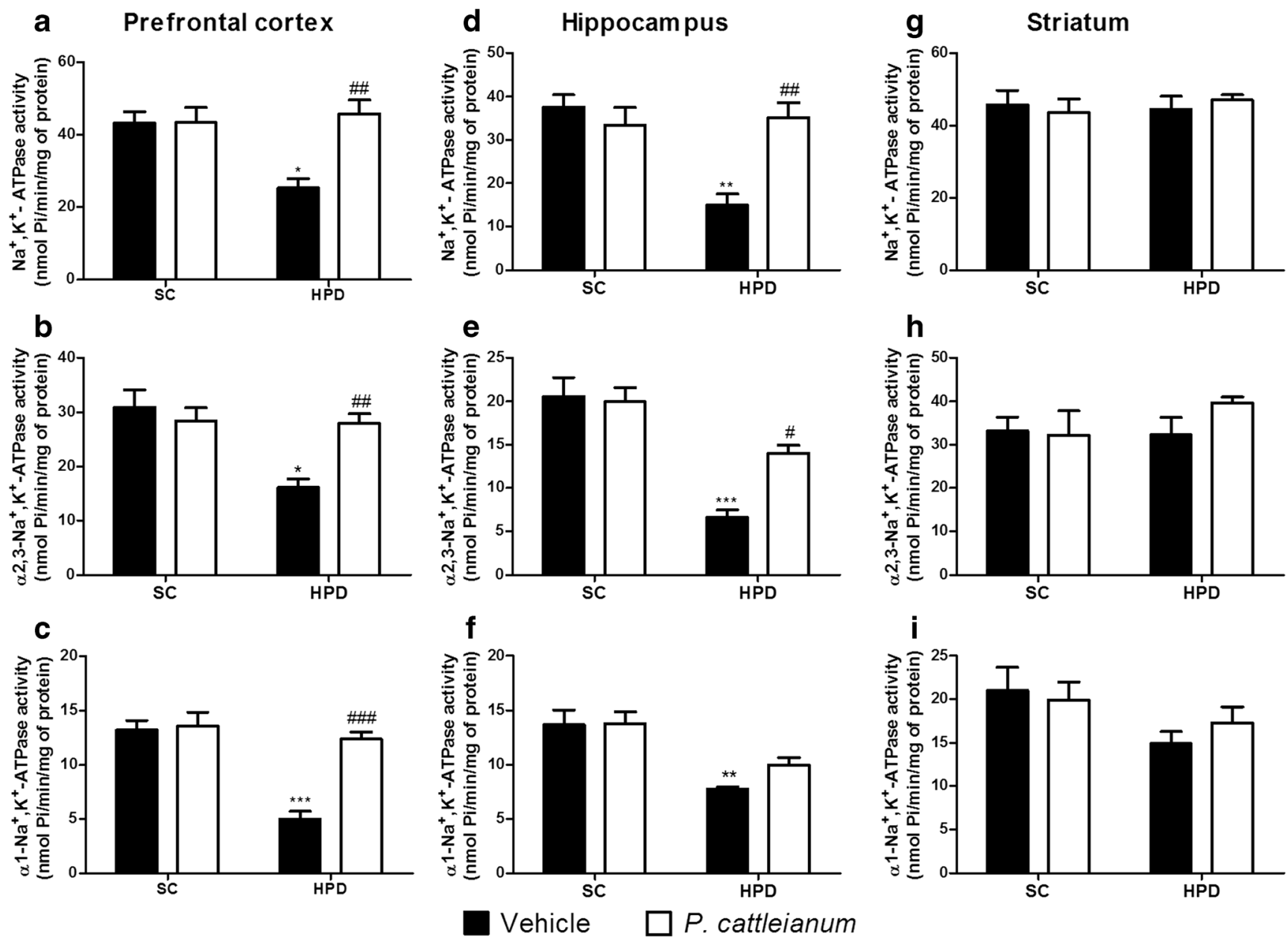

Fig. 4 Effect of $P$. cattleianum (red type) fruit extract treatment in rats exposed to a highly palatable diet on total $\mathrm{Na}^{+}, \mathrm{K}^{+}$-ATPase, $\alpha 2,3-$ and $\alpha 1$ isoform activities in the prefrontal cortex, hippocampus and striatum. Results are expressed as mean \pm S.E.M. ( $\mathrm{n}=5-6$ for group). (***) $P<$ 0.001 when compared with vehicle/SC. $(* *) P<0.01$ when compared

with vehicle/SC. (*) $P<0.05$ when compared with vehicle/SC. $\left({ }^{\# \# \#) ~} P<\right.$ 0.001 when compared with vehicle/HPD. $\left({ }^{\# \#}\right) P<0.01$ when compared with vehicle/HPD. ( $\left.{ }^{\#}\right) P<0.05$ when compared with vehicle/HPD. Twoway ANOVA followed by Bonferroni post-hoc test. SC = Standard Chow; HPD = Highly Palatable Diet 
Table 3 Effect of $P$. cattleianum (red type) extract treatment in rats exposed to a highly palatable diet on oxidative stress parameters in the cerebral structures
Fig. 5 Overview of P. cattleianum (red type) fruit benefits on the metabolic, behavioral and neurochemical alterations induced in an experimental model of metabolic syndrome

\begin{tabular}{lllll}
\hline Parameters & SC/Vehicle & SC/P. cattleianum & HPD/Vehicle & HPD/P. cattleianum \\
\hline Prefrontal cortex & & & & \\
TBARS levels & $0.99 \pm 0.13$ & $1.05 \pm 0.07$ & $1.83 \pm 0.15^{* * *}$ & $1.11 \pm 0.08^{\# \#}$ \\
Total SH content & $30.44 \pm 3.72$ & $25.92 \pm 1.48$ & $21.06 \pm 2.33$ & $20.79 \pm 3.28$ \\
ROS levels & $46.20 \pm 4.15$ & $47.76 \pm 3.72^{\# \#}$ & $78.51 \pm 4.81^{* * *}$ & $48.03 \pm 4.46^{\# \#}$ \\
Nitrite levels & $0.66 \pm 0.02$ & $0.55 \pm 0.11$ & $1.07 \pm 0.13^{* *}$ & $0.63 \pm 0.05^{\# \#}$ \\
CAT activity & $1.42 \pm 0.11$ & $1.20 \pm 0.19$ & $1.02 \pm 0.10$ & $1.13 \pm 0.06$ \\
SOD activity & $29.26 \pm 2.84$ & $26.61 \pm 0.49$ & $18.66 \pm 1.45^{* *}$ & $26.18 \pm 1.25^{\#}$ \\
GPx activity & $57.76 \pm 3.79$ & $53.83 \pm 3.07$ & $51.78 \pm 2.38$ & $48.46 \pm 3.29$ \\
Hippocampus & & & & \\
TBARS levels & $1.38 \pm 0.10$ & $1.46 \pm 0.09$ & $2.50 \pm 0.18^{* * *}$ & $1.88 \pm 0.04^{\# \#}$ \\
Total SH content & $28.40 \pm 1.93$ & $30.04 \pm 3.00$ & $20.87 \pm 0.95$ & $20.50 \pm 0.91$ \\
ROS levels & $51.64 \pm 3.11$ & $57.13 \pm 2.15^{\# \# \#}$ & $107.86 \pm 11.69^{* * *}$ & $51.04 \pm 2.46^{\# \# \#}$ \\
Nitrite levels & $0.75 \pm 0.03$ & $0.78 \pm 0.04$ & $0.99 \pm 0.03^{* *}$ & $0.71 \pm 0.07^{\# \#}$ \\
CAT activity & $1.60 \pm 0.12$ & $1.65 \pm 0.06$ & $1.05 \pm 0.01^{* *}$ & $1.49 \pm 0.09^{\# \#}$ \\
SOD activity & $32.17 \pm 0.71$ & $32.78 \pm 1.80$ & $21.75 \pm 2.15^{* *}$ & $30.57 \pm 2.04^{\# \#}$ \\
GPx activity & $61.51 \pm 8.02$ & $68.15 \pm 3.64$ & $58.29 \pm 4.61$ & $75.30 \pm 7.81$ \\
Striatum & & & & \\
TBARS levels & $2.23 \pm 0.11$ & $1.87 \pm 0.26$ & $3.50 \pm 0.25^{* * *}$ & $2.30 \pm 0.10^{\# \#}$ \\
Total SH content & $34.28 \pm 0.93$ & $29.80 \pm 0.52$ & $23.11 \pm 1.26^{*}$ & $21.81 \pm 2.58$ \\
ROS levels & $36.07 \pm 2.14$ & $26.58 \pm 1.08^{*}$ & $87.79 \pm 2.58^{* * *}$ & $44.28 \pm 1.99^{\# \# \#}$ \\
Nitrite levels & $0.58 \pm 0.07$ & $0.69 \pm 0.04$ & $0.98 \pm 0.06^{* * *}$ & $0.72 \pm 0.02^{\#}$ \\
CAT activity & $1.74 \pm 0.20$ & $1.67 \pm 0.11$ & $1.11 \pm 0.11^{*}$ & $1.60 \pm 0.14$ \\
SOD activity & $33.82 \pm 4.00$ & $28.87 \pm 1.57$ & $22.29 \pm 1.06^{*}$ & $32.77 \pm 2.60^{\#}$ \\
GPx activity & $72.64 \pm 6.95$ & $79.58 \pm 3.95$ & $87.43 \pm 10.23$ & $82.29 \pm 5.20$ \\
\hline
\end{tabular}

Data are expressed as mean \pm S.E.M. $(n=5-10)$. TBARS levels are reported as nmol TBARS $/ \mathrm{mg}$ of protein, thiol content as nmol TNB/mg of protein, ROS levels as $\mu \mathrm{mol} \mathrm{DCF} / \mathrm{mg}$ of protein, nitrite levels as $\mu \mathrm{mol} / \mathrm{mg}$ of protein, enzyme activities (CAT, SOD, GPx) as units/mg of protein. (***) $P<0.001$ as compared with SC/Vehicle. (**) $P<0.01$ as compared with SC/Vehicle. (*) $P<0.05$ as compared with $\mathrm{SC} /$ Vehicle. $\left.{ }^{\# \# \#}\right) P<0.001$ as compared with HPD/Vehicle. $\left(^{\# \#}\right) P<0.01$ as compared with HPD/Vehicle. $\left({ }^{\#}\right) P<0.05$ as compared with HPD/Vehicle. $\mathrm{SC}=$ Standard Chow $\mathrm{HPD}=$ Highly Palatable Diet. Two-way ANOVA followed by Bonferroni post-hoc test

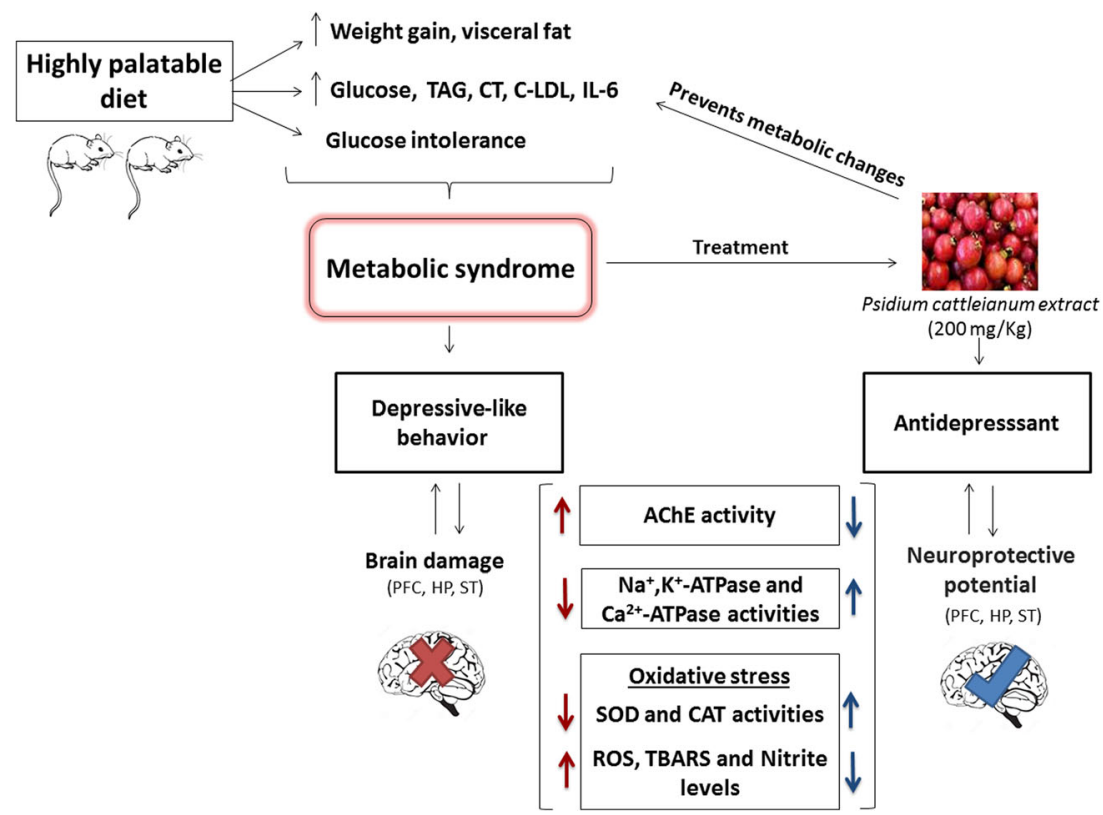


Acknowledgements The Brazilian research funding agencies FAPERGS, CAPES and CNPq supported this study. We also thank Dr. Felipe DalPizzol (Laboratory of Experimental Pathophysiology, University of Southern Santa Catarina, Brazil) for providing the kit to measure IL-6.

\section{Compliance with ethical standards}

Conflict of interest The authors declare that there are no conflicts of interest in this study.

\section{References}

Aebi H (1984) Catalase in vitro. Methods Enzymol 105:121-126 Aksenov MY, Markesbery WR (2001) Changes in thiol content and expression of glutathione redox system genes on the hippocampus and cerebellum in Alzheimer's disease. Neurosci Lett 302:141-145

Ali SF, Lebel CP, Bondy SC (1992) Reactive oxygen species formation as a biomarker of methylmercury and trimethyltin neurotoxicity. Neurotoxicology 13:637-648

Ambrósio G, Kaufmann FN, Manosso L, Platt N, Ghisleni G, Rodrigues ALS, Rieger DK, Kaster MP (2018) Depression and peripheral inflammatory profile of patients with obesity. Psychoneuroendocrinology 91: 132-141

Auberval N, Dal S, Maillard E, Bietiger W, Peronet C, Pinget M, SchiniKerth V, Sigrist S (2017) Beneficial effects of a red wine polyphenol extract on high-fat diet-induced metabolic syndrome in rats. Eur J Nutr 56:1467-1475

Bagul PK, Middela H, Matapally S, Padya R, Bastia T, Madhusudana K, Reddy RB, Chakravarty S, Banerjee SK (2012) Attenuation of insulin resistance, metabolic syndrome and hepatic oxidative stress by resveratrol in fructose-fed rats. Pharmacol Res 66:260-268

Batista KS, Alves AF, Lima MDS, da Silva LA, Lins PP, de Sousa Gomes JA, Silva AS, Toscano LT, de Albuquerque Meireles BRL, de Magalhães Cordeiro AMT, da Conceição ML, de Souza EL, Aquino JS (2018) Beneficial effects of consumption of acerola, cashew or guava processing by-products on intestinal health and lipid metabolism in dyslipidaemic female Wistar rats. Br J Nutr 119:30-41

Bhaswant M, Fanning K, Netzel M, Mathai ML, Panchal SK, Brown L (2015) Cyanidin 3-glucoside improves diet-induced metabolic syndrome in rats. Pharmacol Res 102:208-217

Biegelmeyer R, Andrade JMM, Aboy AL, Apel MS, Dresch RR, Marin R, Raseira MCB, Henriques AT (2011) Comparative analysis of the chemical composition and antioxidant activity of red (Psidium cattleianum) and yellow (Psidium cattleianum var. lucidum) strawberry guava fruit. J Food Sci 76:991-996

Bordignon CL, Francescatto V, Nienow AA, Calvete E, Reginatto FH (2009) Influência do $\mathrm{pH}$ da solução extrativa no teor de antocianinas em frutos de morango. Ciênc Tecnol Aliment 29:183-188

Bradford MA (1976) Rapid and sensitive method for the quantification of microgram quantities of protein utilizing the principle of proteindye binding. Anal Biochem 72:248-254

Bullo CAP, Migo CP, Aranceta J, Salas SJ (2007) Inflammation, obesity and comorbidities: the role of diet. Public Health Nutr 10:1164 1172

Carmona F, Pereira AMS (2013) Herbal medicines: old and new concepts, truths and misunderstandings. Braz J Pharmacog 23:379-385

Carvalho FB, Gutierres JM, Bohnert C, Zago AM, Abdalla FH, Vieira JM, Palma HE, Oliveira SM, Spanevello RM, Duarte MM, Lopes ST, Aiello GM, Amaral G, Pippi NL Andrade CM (2015) Anthocyanins suppress the secretion of proinflammatory mediators and oxidative stress, and restore ion pump activities in demyelination. J Nutr Biochem 26:378-390
Collins B, Hoffman J, Martinez K, Grace M, Lila MA, Cockrell C, Nadimpalli A, Chang E, Chuang CC, Zhong W, Shen W, Cooney P, Hopkins R, Mcintosh M (2016) A polyphenol-rich fraction obtained from table grapes decreases adiposity, insulin resistance, and markers of inflammation and impacts gut microbiota in high-fat fed mice. J Nutr Biochem 31:150-165

Cravotto G, Boffa L, Genzini L, Garella D (2010) Phytotherapeutics: an evaluation of the potential of 1000 plants. J Clin Pharm Ther 35:11-48

Da Silva NA, Rodrigues E, Mercadame AZ, Rosso VV (2014) Phenolic compounds and carotenoids from four fruits native from the Brazilian Atlantic Forest. Agric Food Chem 62:5072-5084

Devalaraja S, Jain S, Yadav H (2011) Exotic fruits as therapeutic complements for diabetes, obesity and metabolic syndrome. Food Res Int 44:1856-1865

Ellman GL, Courtney KD, Andres V, Featherstone RMA (1961) New and rapid colorimetric determination of acetylcholinesterase activity. Biochem Pharmacol 7:88-95

Erlanson-Albertsson C (2005) How palatable food disrupts appetite regulation. Basic Clin Pharmacol Toxicol 97:61-73

Farooqui AA, Farooqui T, Panza F, Frisardi V (2012) Metabolic syndrome as a risk factor for neurological disorders. Cell Mol Life Sci 69:741-762

Fiske CH, Subbarow Y (1927) The nature of the "inorganic phosphate" in voluntary muscle. Sci 65:401-403

Gamaro GD, Streck EL, Matte C, Prediger ME, Wyse AT (2003) Reduction of hippocampal $\mathrm{Na}^{+}, \mathrm{K}^{+}$-ATPase activity in rats subjected to an experimental model of depression. Neurochem Res 28:1339-1344

Gancheva S, Galunska B, Zhelyazkova-Savova M (2017) Diets rich in saturated fat and fructose induce anxiety and depression-like behaviours in the rat: is there a role for lipid peroxidation? Int J Exp Pathol 98:296-306

Gazal M, Kaufmann FN, Acosta BA, Oliveira PS, Valente MR, Ortmann CF, Sturbelle R, Lencina CL, Stefanello FM, Kaster MP, Reginatto FH, Ghisleni G (2015) Preventive effect of Cecropia pachystachya against ketamine-induced manic behavior and oxidative stress in rats. Neurochem Res 40:1421-1430

Guo H, Liu G, Zhong R, Wang Y, Wang D, Xia M (2010) Cyanidin-3-Ob-glucoside regulates fatty acid metabolism via an AMP-activated protein kinase dependent signaling pathway in human HepG2 cells. Int J Mol Sci 11:1365-1402

Halliwell B, Gutteridge JM (2007) Free Radic biol med. Oxford University Press, New York

Hanhineva K, Törrönen R, Bondia-Pons I, Pekkinen J, Kolehmainen M, Mykkänen H, Poutanen K (2010) Impact of dietary polyphenols on carbohydrate metabolism. Int J Mol Sci 11:1365-1402

Huang W, Lin Y, Wang Tsai C, Tseng H, Chen C, Lu P, Chen P, Qian L, Hong J, Lin C (2009) Glycogen synthase kinase-3 negatively regulates anti-inflammatory interleukin-10 for lipopolysaccharideinduced iNOS/NO biosynthesis and RANTES production in microglial cells. Immunol 128:275-286

Huynh TN, Krigbaum AM, Hanna JJ, Conrad CD (2011) Sex differences and phase of light cycle modify chronic stress effects on anxiety and depressive-like behavior. Behav Brain Res 222:212-222

Inhwan IM, Kyung-Ran P, Sung-Moo K, Chulwon K, Jeong HAP, Dongwoo N, Hyeung-Jin J, Bum Sang S, Kyoo Seok A (2012) The butanol fraction of guava (Psidium cattleianum Sabine) leaf extract suppresses MMP-2 and MMP-9 expression and activity through the suppression of the ERK1/2 MAPK signaling pathway. Nutr Cancer 64:255-266

Jayarathne S, Koboziev I, Park O, Oldewage-Theron W, Shen C, Moustaid-Moussa N (2017) Anti-inflammatory and anti-obesity properties of food bioactive components: effects on adipose tissue. Prev Nutr Food Sci 22:251-262

Kade IJ, Rocha JBT (2013) Gallic acid modulates cerebral oxidative stress conditions and activities of enzyme-dependent signaling systems in Streptozotocin-treated rats. Neurochem Res 38:761-771 
Khanal RC, Howard LR, Wilkes SE, Rogers TJ, Ronald L, Prior RL (2012) Effect of dietary blueberry pomace on selected metabolic factors associated with high fructose feeding in growing SpragueDawley rats. J Med Food 15:802-810

Kirshenbaum GS, Saltzman K, Rose B, Petersen J, Vilsen B, Roder JC (2011) Decreased neuronal $\mathrm{Na}^{+}, \mathrm{K}^{+}$-ATPase activity in Atpla3 heterozygous mice increases susceptibility to depression-like endophenotypes by chronic variable stress. Genes Brain Behav 10: $542-550$

Kumar B, Arora V, Kuhad A, Chopra K (2012) Vaccinium myrtillus ameliorates unpredictable chronic mild stress induced depression: possible involvement of nitric oxide pathway. Phytother Res 26: 488-497

Lee J, Durst RW, Wrolstad RE (2005) Determination of total monomeric anthocyanin pigment content of fruit juices, beverages, natural colorants and wines by the $\mathrm{pH}$ differential method: collaborative study. J AOAC Int 8:1269-1278

Liapi C, Kyriakaki A, Zarros A, Galanopoulou P, Al-Humadi H, Dontas I, Voumvourakis K, Tsakiris T (2010) Choline-deprivation alters crucial brain enzyme activities in a rat model of diabetic encephalopathy. Metab Brain Dis 25:269-276

Lowry OH, Rosebrough NJ, Farr AL, Randall RJ (1951) Protein measurement with the Folin phenol reagent. J Biol Chem 193:265-275

Madani Z, Malaisse WJ, Ait-Yahia D (2015) A comparison between the impact of two types of dietary protein on brain glucose concentrations and oxidative stress in high fructose-induced metabolic syndrome rats. Biomed Reports 3:731-735

Manzano S, Williamson G (2010) Polyphenols and phenolic acids from strawberry and apple decrease glucose uptake and transport by human intestinal Caco-2 cells. Mol Nutr Food Res 54:1773-1780

Mattos Jr. (1989) Myrtaceae do Rio Grande do Sul. Porto Alegre: CEUE. pp.721

Melo JB, Agostinho P, Oliveira CR (2003) Involvement of oxidative stress in the enhancement of acetylcholinesterase activity induced by amyloid beta-peptide. Neurosci Res 45:17-127

Miliauskas G, Venskutonis PR, Van TA (2004) Screening of radical scavenging activity of some medicinal and aromatic plant extracts. Food Chem 85:231-237

Misra HP, Fridovich I (1972) The role of superoxide anion in the autoxidation of epinephrine and a simple assay for superoxide dismutase. J Biol Chem 247:3170-3175

Nishi A, Fisone G, Snyder GL, Dulubova I, Aperia A, Nairn AC, Greengard P (1999) Regulation of $\mathrm{Na}^{+}, \mathrm{K}^{+}$-ATPase isoforms in rat neostriatum by dopamine and protein kinase C. J Neurochem 73: $1492-1501$

Ohkawa H, Ohishi N, Yagi K (1979) Assay for lipid peroxides in animal tissues by thiobarbituric acid reaction. Anal Biochem 95:351-358

Oliveira PS, Gazal M, Flores NP, Zimmer AR, Chaves VC, Reginatto FH, Kaster MP, Tavares RG, Spanevello RM, Lencina CL, Stefanello FM (2017a) Vaccinium virgatum fruit extract as an important adjuvant in biochemical and behavioral alterations observed in animal model of metabolic syndrome. Biomed Pharmacother 88:939-947

Oliveira PS, Chaves VC, Bona NP, Soares MSP, Cardozo JS, Vasconcellos FA, Tavares RG, Vizzotto M, Da Silva LMC, Grecco FB, Gamaro GD, Spanevello RM, Lencina CL, Reginatto FH, Stefanello FM (2017b) Eugenia uniflora fruit (red type) standardized extract: a potential pharmacological tool to diet-induced metabolic syndrome damage management. Biomed Pharmacother 92: 935-941

Paredes-Lopez O, Cervantes-Ceja ML, Vigna-Perez M, Hernandez-Perez $\mathrm{T}$ (2010) Berries: improving human health and healthy aging, and promoting quality life. Plant Foods Hum Nutr 65:299-308
Quines CB, Rosa SG, Velasquez D, Da Rocha JT, Neto JSS, Nogueira CW (2016) Diphenyldiselenide elicits antidepressant-like activity in rats exposed to monosodium glutamate: a contribution of serotonin uptake and $\mathrm{Na}^{+}, \mathrm{K}^{+}$-ATPase activity. Behav Brain Res 301:161-167

Rambo LM, Ribeiro LR, Schramm VG, Berch AM, Stamm DN, DellaPace ID, Silva LF, Furian AF, Oliveira MS, Fighera MR, Royes LF (2012) Creatine increases hippocampal $\mathrm{Na}(+), \mathrm{K}(+)$-ATPase activity via NMDA-calcineurin pathway. Brain Res Bull 88:553-559

Raskin I, Ripoll C (2004) Can an apple a day keep the doctor away? Curr Pharm Des 10:3419-3429

Ribeiro AB, Chisté RC, Freitas M, Da Silva AF, Visentainer JV, Fernandes E (2014) Psidium cattleianum fruit extracts are efficient in vitro scavengers of physiologically relevant reactive oxygen and nitrogen species. Food Chem 165:140-148

Rudolf S, Greggersen W, Kahl KG, Huppe US (2014) Elevated IL-6 levels in patients with atypical depression but not in patients with typical depression. Psychiatry Res 217:34-38

Shah A, Mehta N, Reilly MP (2008) Adipose inflammation, insulin resistance, and cardiovascular disease. J Parenter Enter Nutr 32:638 644

Sharma D, Setthi P, Hussain E, Singh R (2009) Curcumin counteracts the aluminium-induced ageing-related alterations in oxidative stress, $\mathrm{Na}+\mathrm{K}+$ ATPase and protein kinase $\mathrm{C}$ in adult and old rat brain regions. Biogerontology 10:489-502

Silva L, Figueiredo E, Ricardo N, Vieira L, Figueiredo R, Brasil L, Gomes C (2014) Quantification of bioactive compounds in pulps and by-products of tropical fruits from Brazil. Food Chem 143:398 404

Singleton VL, Orthefer R, Lamuela-Ranventós, R (1999). Analysis of total phenols and other oxidation substrates and antioxidants by means of Folin-Ciocalteau reagent. In: Methods Enzymol, (Parker L, ed.) (pp. 152-159). Academic Press, Section III

Srikanthan K, Shapiro JI, Sodhi K (2016) The role of Na/K-ATPase signaling in oxidative stress related to obesity and cardiovascular disease. Molecules 21:1-13

Tey SL, Lee DEM, Henry CJ (2017) Fruit form influences postprandial glycemic response in elderly and young adults. J Nutr Health Aging 21:887-891

Treviño S, Aguilar-Alonso P, Flores Hernandez JA, Brambila E, Guevara J, Flores G, Lopez-Lopez G, Muñoz-Arenas G, Morales-Medina JC, Toxqui V, Venegas B, Diaz A (2015) A high calorie diet causes memory loss, metabolic syndrome and oxidative stress into hippocampus and temporal cortex of rats. Synapse 69:421-433

Vendrame S, Del Bo' C, Ciappellano S, Riso P, Klimis-Zacas D (2016) Berry fruit consumption and metabolic syndrome. Antioxidants 5: $1-21$

Wellen KE, Thompson CB (2010) Cellular metabolic stress: considering how cells respond to nutrient excess. Mol Cell 40:323-332

Williamson EM (2001) Synergy and other interaction in phytomedicines. Phytomedicine 8:401-409

Zarros A, Liapi C, Galanopoulou P, Marinou K, Mellios Z, Skandali N, Al-humadi H, Anifantaki F, Gkrouzman E, Tsakiris S (2009) Effects of adult-onset streptozotocin-induced diabetes on the rat brain antioxidant status and the activities of acetylcholinesterase, $\left(\mathrm{Na}^{+}, \mathrm{K}^{+}\right)$and $\mathrm{Mg}^{2+}$-ATPase: modulation by L-cysteine. Metab Brain Dis 24: 337-348

Zhang XY, Yao JK (2013) Oxidative stress and therapeutic implications in psychiatric disorders. Prog Neuropsychopharmacol Biol 46:197199 